\title{
Assessment of Ghana's Progress towards Attainment of Millenium Development Goal 6, Target a - A Review of Sentinel Survey Data
}

\author{
Article by Owusu Oduro Paul \\ Public Health, Texila American University, Ghana \\ E-mail:plowusu@yahoo.co.uk
}

\begin{abstract}
Human immunodeficiency virus infection and acquired immune deficiency syndrome (HIV/AIDS) is a spectrum of conditions caused by infection with the human immunodeficiency virus $(H I V)$ [1, 2, 3].

$H I V$ is spread primarily by unprotected sex (including anal and oral sex), contaminated blood transfusions, hypodermic needles, and from mother to child during pregnancy, delivery, or breastfeeding [4].

In 2015, about 37.3 million people were living with HIV and it resulted in 1.2 million deaths [5, 6]. Most of those infected live in sub-Saharan Africa [7]. Between its discovery and 2014 AIDS has caused an estimated 39 million deaths worldwide [8]. HIV/AIDS is considered a pandemic-a disease outbreak which is present over a large area and is actively spreading [9].HIV is believed to have originated in west-central Africa during the late 19th or early 20th century [10].AIDS was first recognized by the United States Centers for Disease Control and Prevention (CDC) in 1981 and its cause-HIV infectionwas identified in the early part of the decade [11].

HIV was first confirmed in Ghana at the Noguchi Memorial Institute for Medical Research in 1986 [12, 13]. The infection has since spread to all parts of the country and is established within the whole society. The national prevalence as at 2015 was 1.37\% with Greater Accra recording the highest prevalence by region [14]. At the Millennium Summit in September 2000 the largest gathering of world leaders in history adopted the UN Millennium Declaration, committing their nations to a new global partnership to reduce extreme poverty and setting out a series of time-bound targets, with a deadline of 2015, which have become known as the Millennium Development Goals. The Millennium Development Goals (MDGs) are the world's time-bound and quantified targets for addressing extreme poverty in its many dimensions-income poverty, hunger, disease, lack of adequate shelter, and exclusion-while promoting gender equality, education, and environmental sustainability [15].

Since the first case of HIV was diagnosed, enormous national and international efforts and resources have been expended through the National HIV and AIDS response to contain the epidemic [16, 17, 18].

Following the Declaration of commitment of the United Nations General Assembly Special Session on HIV/AIDS in 2001, the Government of Ghana earmarked 15\% of its health budget for HIV/AIDS activities with support from multilateral partners including the World Bank [19].

MDG 6 specifically addresses HIV/AIDS with the following targets;

To halt by 2015 and have started to reverse the spread of HIV/AIDS

To achieve global access to treatment for HIV/AIDS for those who need it by 2010[20].

The goal of this study is to review Ghana's progress on MDG 6 using the HIV Sentinel Survey (HSS) report.
\end{abstract}

\section{Methods}

The NACP under the Ghana Health Service provides comprehensive HIV and AIDS services to all persons living with HIV and AIDS in Ghana. As of the end of 2010, over 1,000 testing and Counseling and PMTCT Centres, and over 140 ART Centres were available in the country for HIV and AIDS services $[21,22]$. 
DOI: $10.21522 / \mathrm{TIJPH} .2013 .05 .04 . \mathrm{Art} 002$

ISSN: $2520-3134$

The annual reports contain data on reported HIV and AIDS cases. Data on reported AIDS cases is collected using the universal case reporting system i.e. Integrated Disease Surveillance Response (IDSR). HIV testing and counseling (HTC) is done by well trained counselors in all health facilities and the HTC services are free. In this study we reviewed HIV sentinel survey (HSS) reports and annual reports of the NACP from 2000-2015. The HSS report is produced annually from sentinel surveys across all sentinel sites in the country and the annual reports provide a summary of all activities and service provision data by the NACP.

AIDS case reporting has been used by the Ministry of Health to assess the magnitude of the HIV and AIDS problem in all the ten regions and provide an approximate picture of the distribution of AIDS cases and changes over time in the country [23]. HIV sentinel survey in Ghana. The HIV Sentinel Survey (HSS) is a cross sectional survey targeting women attending antenatal clinics in selected ANC sites in Ghana. The annual HIV sentinel surveillance system was initiated in 1992.

It is based on the premise that prevalence of HIV among pregnant women is a good proxy indicator of the spread of infection among the populace and has been the primary data source for National HIV and AIDS estimates in Ghana. Sentinel sites have been established in all ten regions of Ghana; each region has at least three sites. The number of sites has increased over the years from 24 in 2002, to 35 in 2004 and to 40 since 2005. The increase ensures a balanced representation of rural/urban areas in the determination of HIV prevalence in Ghana.

\section{Data source}

\section{Selection of sentinel survey site}

Selection of sentinel sites follow strict predetermined criteria with the aim of ensuring sites are located in different geographic areas and represent each geographical region in the country. Each of the ten regions has at least three sites including a minimum of one rural site. All selected sites provide antenatal care and sexually transmitted infection (STI) services.

\section{Study population}

The populations for HIV sentinel surveillance are adults aged 15 to 49 years including, pregnant women attending antenatal clinics (ANC) and male and female clients seeking treatment for Sexually Transmitted Infections (STIs) at STI Clinics during the survey period. All first time ANC clients within the survey period are eligible for inclusion and those reporting for repeated visits are excluded. Samples are collected through unlinked anonymous methods (i.e samples have code numbers not names). Basic data including age, sex, date of collection, name of site; district and region are recorded on site.

\section{Testing}

The World Health Organization's HIV Testing Strategy II for surveillance (14) is used to screen the samples. The laboratories at the peripheral sentinel sites and regional level use Rapid Tests (First Response I and II) and confirmation for HIV is done at the National Public Health Reference Laboratory (PHRL) in Accra using Immunoblot (INNOLIA). Sample screening at the sentinel site is done soon after collection or sera stored at 2-8 degrees centigrade for not more than 3 days. All samples at urban sites are screened at the site and samples from rural sites are stored (not more than 3 days) and transferred to an urban testing site for immediate testing. The Public Health Reference Laboratory currently holds all samples submitted for confirmation for a period not less than three years.

\section{Quality assurance measures in HIV sentinel survey in ghana}

Early selection and evaluation of test kits and training of laboratory staff are done prior to each annual survey. All reactive samples are re-tested at the PHRL for confirmation and $10 \%$ of all non-reactive samples are also randomly selected from each sentinel site and tested at PHRL. External Quality Assurance Testing is also employed; two reactive samples and three non-reactive samples from each site 
are sent to the Noguchi Memorial Institute for Medical Research (NMIMR) in Accra, for testing. NMIMR is the external quality assurance institution [24].

\section{Results}

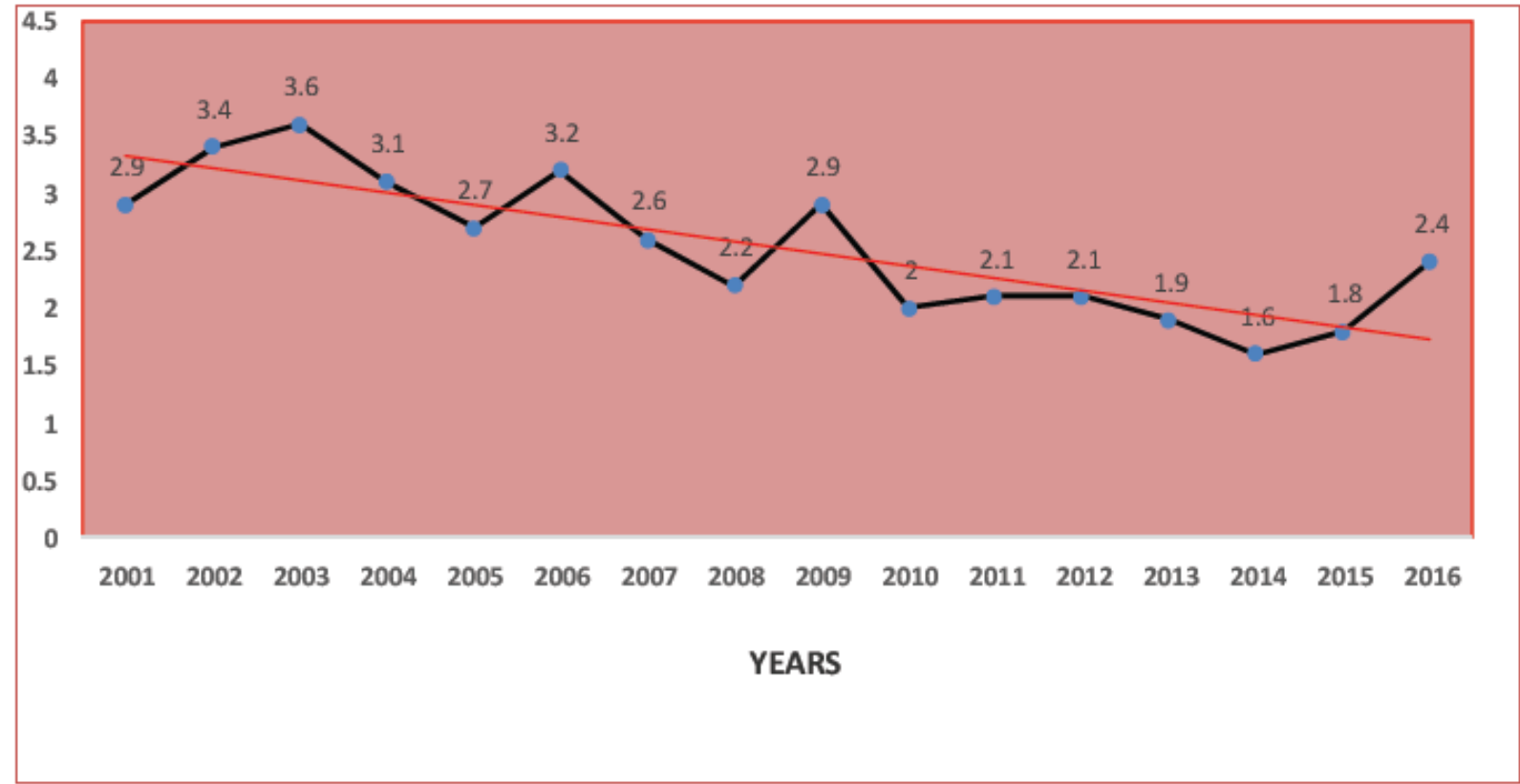

Figure 1. Median HIV prevalence, 2001 - 2016 with linear trend

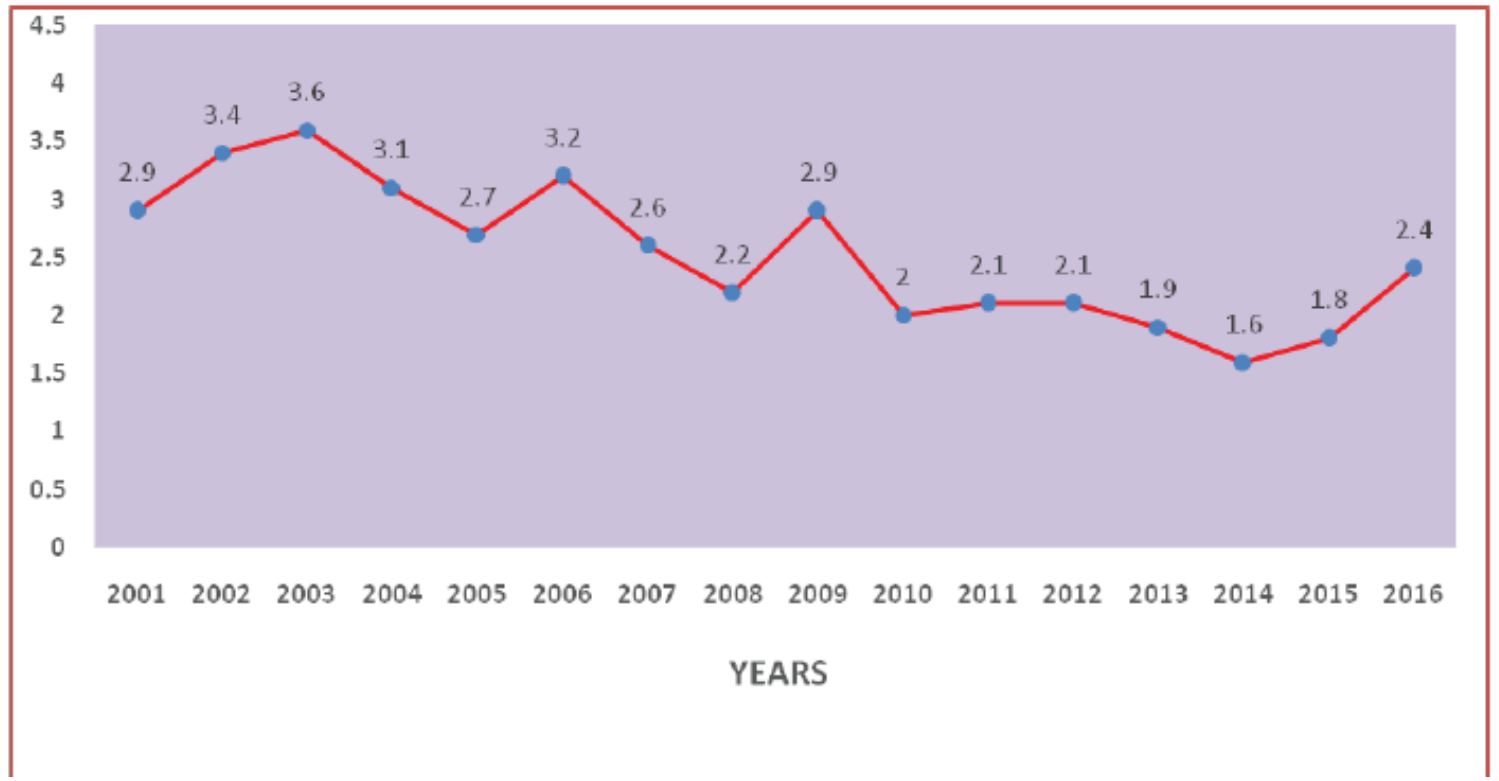

Figure 2. Median HIV prevalence, 2001-2016 
DOI: $10.21522 / \mathrm{TIJPH} .2013 .05 .04 . A r t 002$

ISSN: $2520-3134$

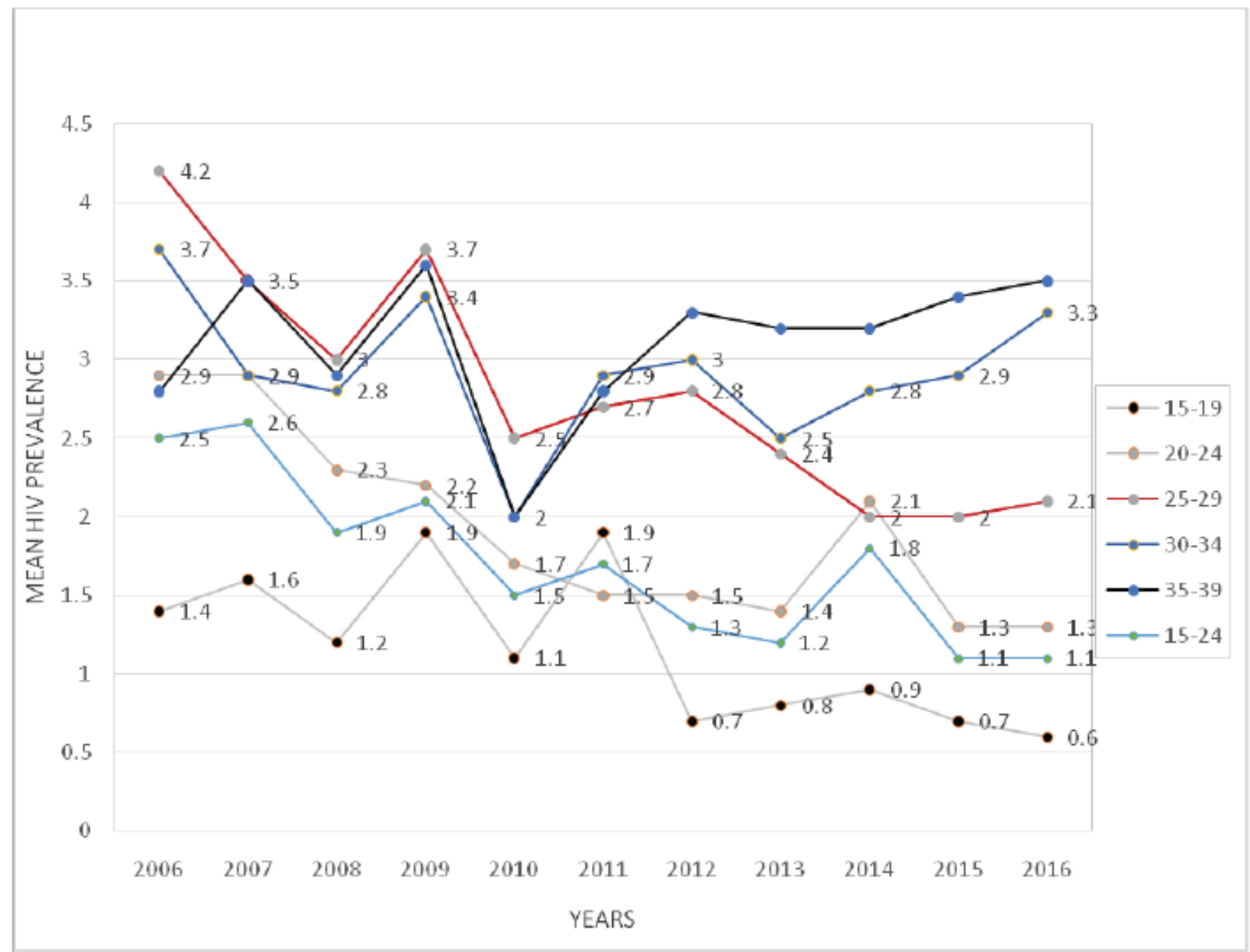

Figure 3. Trends in HIV prevalence by age group, 2006 - 2016

\section{Discussion, recommendations}

HIV prevalence data is critical for planning and implementation of programs within the national response.

This study reviewed National AIDS/STI Control Programme data of Ghana's HIV epidemic over the period 2001 - 2015 in an attempt to assess Ghana's progress towards achieving MDG Goal 6 on HIV/AIDS, which is to halt by 2015 and have started to reverse the spread of HIV/AIDS.

The HIV prevalence over the years, describes Ghana's epidemic as generalized according to W.H.O. classification (HIV is firmly established in the general population. Numerical proxy: HIV prevalence consistently exceeding $1 \%$ among pregnant women (25). 1 .

The linear trend analysis from 2001 to 2015 shows a declining HIV prevalence as illustrated in figure

Efforts that have resulted in this should be strengthened or intensified.

This review showed that the HIV prevalence was highest among the most economic productive age group (20-49 years) (Figure 3) which agrees with global trends of HIV infections (19) at all times.

The HIV epidemic is established within the whole society and sub-populations with higher prevalence and risk of transmission constitute a reservoir for sustaining the epidemic $(2,3)$ and thus although Ghana's HIV prevalence is low, the epidemic continues to pose enormous challenges to health and social systems of the nation as it has serious health, economic and social implications for the entire population. 
The HIV prevalence remained fairly steady from 2009-2012 and saw a decline consecutively in 2013 and 2014 giving the assurance that the country was on the road of reversing the spread of HIV infection.

This decline, however, couldn't be sustained as there was a rise in the National prevalence from $1.6 \%$ in 2014 to $1.8 \%$ in 2015, dashing hopes of a sustained reduction of HIV prevalence. This is even more worrying as the recently published 2016 prevalence (2.4\%) saw a further increase from the 2015 prevalence. This increase may be as a result of the global economic downturn and resultant dwindling donor funds.

This has had great impact on mass media campaign against HIV/AIDS as advertisements are no longer common on our airwaves, print and electronic media like they used to be.

Because sexual contact happens to be the route of transmission for most of the HIV infections (26) and because the majority of the reservoir of infection falls within the sexually active age groups, constant reminders on the devastating effects of HIV/AIDS by way of advertisements will be important in instilling and sustaining the right sexual behaviors in order to further reduce the spread of the infection.

Government/ministries/agencies locally need to generate and commit more resources (especially in the era of dwindling donor funds) to fighting the HIV epidemic through support for behavior change, communication programmers, HIV testing and counseling, provision of ART, prevention of Mother-toChild transmission of HIV, early infant diagnosis of HIV, prevention and management of STI's including condom use, safety in blood and blood products, advocacy and research.

\section{Conclusion}

Ghana has been able to meet the MDG 6 on HIV/AIDS. The country started with a national prevalence rate of $2.3 \%$ in the year 2000 and as at 2015, the national prevalence stood at $1.8 \%$. This came about as a result of sustained national and international efforts from all stakeholders.

Even though there has been a reduction in linear trends over the years under review, the HIV prevalence has seen a gradual increase in 2015(1.8\%) from the $2014(1.6 \%)$ national prevalence and the recently published $2016(2.4 \%)$ prevalence also saw an increase over the 2015 prevalence which makes this trend very worrying.

The efforts which brought about the decline in HIV prevalence till 2014 need to be intensified in order to further reduce the rate of infection in the country.

\section{References}

[1]. Alexander Krämer, Mirjam Kretzschmar, Klaus Krickeberg, (2010). Modern infectious disease epidemiology concepts, methods, mathematical models, and public health (Online-Ausg. ed). New York: Springer. p. 88. ISBN 9780387938356.

[2]. Ampofo WK. HIV Care and Support Services in Ghana. Ghana Med J 2005; 43 : 142-143

[3]. Baiden F, Akanlu G, Hodgson A, Akweongo P, Debpuur C, Binka F . Using lay counselors to promote Community-based voluntary counseling and HIV testing in rural Northern Ghana: a baseline survey on community acceptance and stigma. J Biosoc Sci 2007; 39: 721-733.

[4]. "Basic Statistics". CDC. November 3, 2015. Retrieved 11 February 2016.

[5]. GBD 2015 Disease and Injury Incidence and Prevalence, Collaborators. (8 October 2016). "Global, regional, and national incidence, prevalence, and years lived with disability for 310 diseases and injuries, 1990-2015: a systematic analysis for the Global Burden of Disease Study 2015." Lancet (London, England). 388 (10053): 15451602. doi:10.1016/S0140-6736(16)31678-6. PMC 5055577. PMID 27733282.

[6]. Gallo RC (2006). "A reflection on HIV/AIDS research after 25 years". Retrovirology. 3 (1): 72. doi:10.1186/1742-4690-3-72. PMC 1629027. PMID 17054781.

[7]. Gallo RC (2006). "A reflection on HIV/AIDS research after 25 years". Retrovirology. 3 (1): 72 . doi: 10.1186/1742-4690-3-72. PMC 1629027. PMID 17054781.

[8]. GBD 2015 Mortality and Causes of Death, Collaborators. (8 October 2016). "Global, regional, and national life expectancy, all-cause mortality, and cause-specific mortality for 249 causes of death, 1980-2015: a systematic 
DOI: $10.21522 / \mathrm{TIJPH} .2013 .05 .04 . A r t 002$

ISSN: $2520-3134$

analysis for the Global Burden of Disease Study 2015". Lancet (London, England). 388 (10053): 1459-1544. doi: 10.1016/s0140-6736(16)31012-1. PMID 27733281.

[9]. Ghana Health Service. 2006 Annual Report. National AIDS/STI control program 2007, Accra-Ghana.

[10]. Ghana Health Service. 2006 Annual Report. National AIDS/STI control program 2007, Accra-Ghana.

[11]. Ghana Health Service. 2009 Annual Report. National AIDS/STI control program 2010, Accra Ghana.

[12]. Ghana Health Service. 2010 HIV Sentinel Survey Report. National AIDS/STI control program 2011, AccraGhana

[13]. "HIV/AIDS Fact sheet $\mathrm{N}^{\circ} 360 "$. WHO. November 2015. Retrieved 11 February 2016.

[14]. Kallings LO (2008). "The first postmodern pandemic: 25 years of HIV/AIDS". Journal of Internal Medicine. 263 (3): 218-43. doi: 10.1111/j.1365-2796.2007.01910.x. PMID 18205765. (subscription required)

[15]. Markowitz, edited by William N. Rom; associate editor, Steven B. (2007). Environmental and occupational medicine (4th ed). Philadelphia: Wolters Kluwer/Lippincott Williams \& Wilkins. p. 745. ISBN 978-0-7817-6299-1.

[16]. Neequaye JE, Neequaye AR, Mingle JA, OforiAdjei D, Osei-Kwasi M, Grant F, Hayami M, Ishikawa K, Biggar RJ. Sexual habits and social factors in local Ghanaian prostitutes which could affect the spread of human immune deficiency virus (HIV). Ghana Med J 1987; 21: 12-15.

[17]. Neequaye JE, Neequaye AR, Mingle JA, Ofori Adjei D, Osei-Kwasi M, Grant F, Hayami M, Ishikawa K, Biggar RJ. Sexual habits and social factors in local Ghanaian prostitutes which could affect the spread of human immune deficiency virus (HIV). Ghana Med J 1987; 21: 12-15.

[18]. Sepkowitz KA (June 2001). "AIDS - the first 20 years". N. Engl. J. Med. 344 (23): 1764-72. doi: 10.1056/NEJM200106073442306. PMID 11396444.

[19]. Sharp, PM; Hahn, BH (September 2011). "Origins of HIV and the AIDS Pandemic". Cold Spring Harbor perspectives in medicine. 1 (1): a006841. doi: 10.1101/cshperspect.a006841. PMC 3234451. PMID 22229120.

[20]. Shisana O, Rehle T, Simbayi L, Parker W, Zuma K, Bhana A. South African National HIV Prevalence, HIV Incidence, Behaviour and Communication Survey, 2005. Cape Town, South Africa: Human Sciences Research Council.

[21]. Wilhelm Kirch (2008). Encyclopedia of public health. New York: Springer. pp. 676-677. ISBN 9781402056130

[22]. www.who.int $>$ hiv $>$ HIVCP_GHA

[23]. www.un.org $>$ milleniumgoals $>$ aids

[24]. www.who.int

[25]. www.nature.com/nrmicro/journal/v2/n1/full/nrmicro794.html?

[26]. www.citifmonline.com

[27]. www.unmilleniumproject.org 